\title{
Lophozonia tree cavities used for nesting by Slender-billed Parakeets (Enicognathus leptorhynchus) in the central valley of southern Chile: a potentially vanishing keystone resource
}

Thomas H. White Jr. ${ }^{*}$ (10 and Jaime E. Jiménez ${ }^{2,3,4}$

\begin{abstract}
Background: The Slender-billed Parakeet (Enicognathus leptorhynchus) is a psittacine endemic to southern Chile and an obligate secondary cavity-nester. In the central valley of southern Chile, most (94\%) of the known Slender-billed Parakeet nests have occurred in large, mature southern beech (Lophozonia obliqua) trees (locally known as "pellines"). As relicts of the original old-growth forests of southern Chile, most pellines have been lost due to extensive landclearing throughout the region, potentially threatening long-term persistence of the Slender-billed Parakeet.

Methods: We conducted our study in the central valley of southern Chile, near the city of Osorno during three consecutive nesting seasons (November-January, 2008-2011). Nest trees used by Slender-billed Parakeets were located by direct observation of parakeet activities and through interviews with local residents, some of whom were former parrot nest poachers. Nest cavities were accessed, inspected and measured using single-rope climbing techniques. We report means, standard errors, 95\% confidence intervals and ranges for 11 cavity-related variables. We also report clutch sizes encountered in active nests, and age estimates of nest trees based on known growth rates of Lophozonia trees in southern Chile. Linear regressions were used to evaluate potential relationships between cavity-related variables and clutch size.
\end{abstract}

Results: We located and measured 38 Lophozonia tree cavities used for nesting by Slender-billed Parakeets. Compared to those used by other psittacines, nest trees were relatively large, averaging $30.4 \pm 1.1 \mathrm{~m}$ in height with a mean diameter at breast height of $134.5 \pm 4.7 \mathrm{~cm}$. Based on estimated annual diameter increment, ages of nest trees ranged from approximately 209-485 years. Nest cavities entrances averaged $12.5 \pm 0.9 \mathrm{~m}$ in height above ground level. Cavity entrance widths averaged $51.0 \pm 13.3 \mathrm{~cm}$ (vertical) by $11.5 \pm 0.7 \mathrm{~cm}$ (horizontal). Cavity entrance orientations were apparently random, with no directional preferences detected. Nest cavities were also relatively large, with a mean internal diameter of $39.6 \pm 2.4 \mathrm{~cm}$ and mean depth of $90.3 \pm 24.2 \mathrm{~cm}$. Clutch sizes (2-9) were unusually large for psittacines of this size (ca. 280-300 g) and broods of up to seven well-developed nestlings were observed.

Conclusions: We found that the deep and spacious cavities provided by pellines facilitate successful rearing of large broods, thereby maximizing productivity and fitness. The existence of pellines has apparently allowed Slender-billed Parakeets to adapt successfully to a wholesale loss of ancestral habitat to anthropogenic modifications. Immediate and strategic conservation measures, such as protection of existing pellines and the regeneration and recruitment of additional ones, are recommended for ensuring the survival of Slender-billed Parakeet populations throughout the central valley of southern Chile.

\footnotetext{
*Correspondence: thomas_white@fws.gov

1 Puerto Rican Parrot Recovery Program, United States Fish and Wildlife

Service, Box 1600, Rio Grande, PR 00745, USA

Full list of author information is available at the end of the article
} 
Keywords: Conservation, Deforestation, Habitat loss, Lophozonia obliqua, Pellines, Psittacidae, Regeneration

\section{Background}

The availability of suitable nest cavities is essential for the survival and persistence of secondary cavity-nesting species (Newton 1994; Cockle et al. 2010; Bunnell 2013). For such species that specifically use arboreal cavities, cavity suitability can depend upon factors such as internal cavity dimensions, entrance height and orientation and even particular tree species (Snyder et al. 1987; Martin et al. 2004; Cockle et al. 2012; Renton et al. 2015). This specificity in nest requirements can result in substantial limitations to cavity availability, especially in humanmodified environments (Cockle et al. 2010; Edworthy and Martin 2013; Saunders et al. 2014). Although attrition and localized loss of tree cavities occur naturally over time (Wesołowski 2007; Edworthy et al. 2012), anthropogenic activities (e.g. logging, land clearing) can result in accelerated and sustained loss, drastically reducing cavity availability at larger spatio-temporal scales (Cornelius et al. 2008; Cockle et al. 2010; Edworthy and Martin 2013). For secondary cavity-nesters, limitations or reductions in nest cavity availability can increase both inter- and intra-specific competition, increase predation, decrease reproductive success and potentially threaten population viability and persistence (Snyder et al. 1987; Renton 2004; Cockle et al. 2010; Jiménez and White 2011).

The Slender-billed Parakeet (Enicognathus leptorhynchus) is a medium-sized (ca. 280-300 g) psittacine endemic to southern Chile and, like most psittacines, an obligate secondary cavity nester. One of only two species in its genus, the Slender-billed Parakeet (hereafter SBP) has one of the most southerly ranges of any psittacine $\left(34^{\circ} \mathrm{S}-44^{\circ} \mathrm{S}\right.$; Ridgely et al. 2005), second only to its congeneric Austral Parakeet (Enicognathus ferrugineus; Díaz and Kitzberger 2006). Although considered of "Least Concern" globally (IUCN 2015), the Chilean government considers the species as "Vulnerable" in southern Chile due to an apparent population decline (SAG 2008), but there has been little research into the reasons for this decline. In fact, only recently some habitat requirements of this species have become known (Peña-Foxon et al. 2011; Carneiro et al. 2011, 2013), among which large, mature trees with ample cavities are essential. However, to date there has been no comprehensive quantitative description of the actual nesting cavities used by SBP in the central valley of southern Chile, an extensive area which has undergone dramatic landscape-level changes in habitat composition over the past century (Echeverría et al. 2006, 2007; Lara et al. 2012). These changes have resulted in an estimated loss of up to $98 \%$ of the original old-growth Lophozonia (formerly of the genus Nothofagus; see Heenan and Smissen 2013) forests, with only around 4000 ha remaining as scattered fragments or isolated trees (Salas et al. 2006; Escanilla 2012). These relict Lophozonia forests are internationally recognized for their uniqueness and high biodiversity value (Myers et al. 2000; Echeverría et al. 2012).

In this paper, we describe and quantify characteristics of southern beech (Lophozonia obliqua) trees and their associated cavities used for nesting by SBP in the central valley of southern Chile. This is the dominant tree species used for nesting by SBP in the region, accounting for at least $94 \%$ of all reported nesting cavities to date (Carneiro et al. 2013). Accordingly, old-growth L. obliqua likely plays a key role in the ecology of SBP throughout the region, as suggested by Carneiro et al. (2013). Thus, any information on how SBP currently utilizes these relict forest fragments with large, but isolated trees is essential for habitat conservation planning aimed at maintaining and perpetuating the SBP throughout the region. We also highlight comparisons and relationships between our findings and those reported for other cavity-nesting psittacines worldwide (see Rivera et al. 2011; Renton et al. 2015), including suggestions for future research on SBP nesting ecology. We further discuss current threats to this unique forest resource and how these may affect future population persistence of the SBP in southern Chile.

\section{Methods \\ Study area}

We conducted our study in the central valley of southern Chile, near the city of Osorno $\left(40^{\circ} 42^{\prime} \mathrm{S}, 73^{\circ} 10^{\prime} \mathrm{W}\right.$; Fig. 1$)$. Originally comprised of continuous lowland temperate forests dominated by L. obliqua, Persea lingue, Aextoxicon punctatum and Laurelia sempervirens (Veblen et al. 1979), the central valley now consists of an extensive agricultural matrix of wheat, oat, potato and tulip crops interspersed with cattle pastures (Echeverría et al. 2006; Carneiro et al. 2011). Small dispersed stands of native second-growth forests and remnant fragments of old-growth forests, as well as scattered and isolated trees, comprised mainly of mature individual trees of $L$. obliqua (locally known as "pellines"), persist throughout the area (Salas et al. 2006; Jiménez and White 2011). The area climate is classified as oceanic wet-temperate (Köppen climate classification $C f b$; Kottek et al. 2006) with an average annual precipitation of $1383 \mathrm{~mm}$ and average temperature of $11.4{ }^{\circ} \mathrm{C}$ (Carneiro et al. 2013). The 


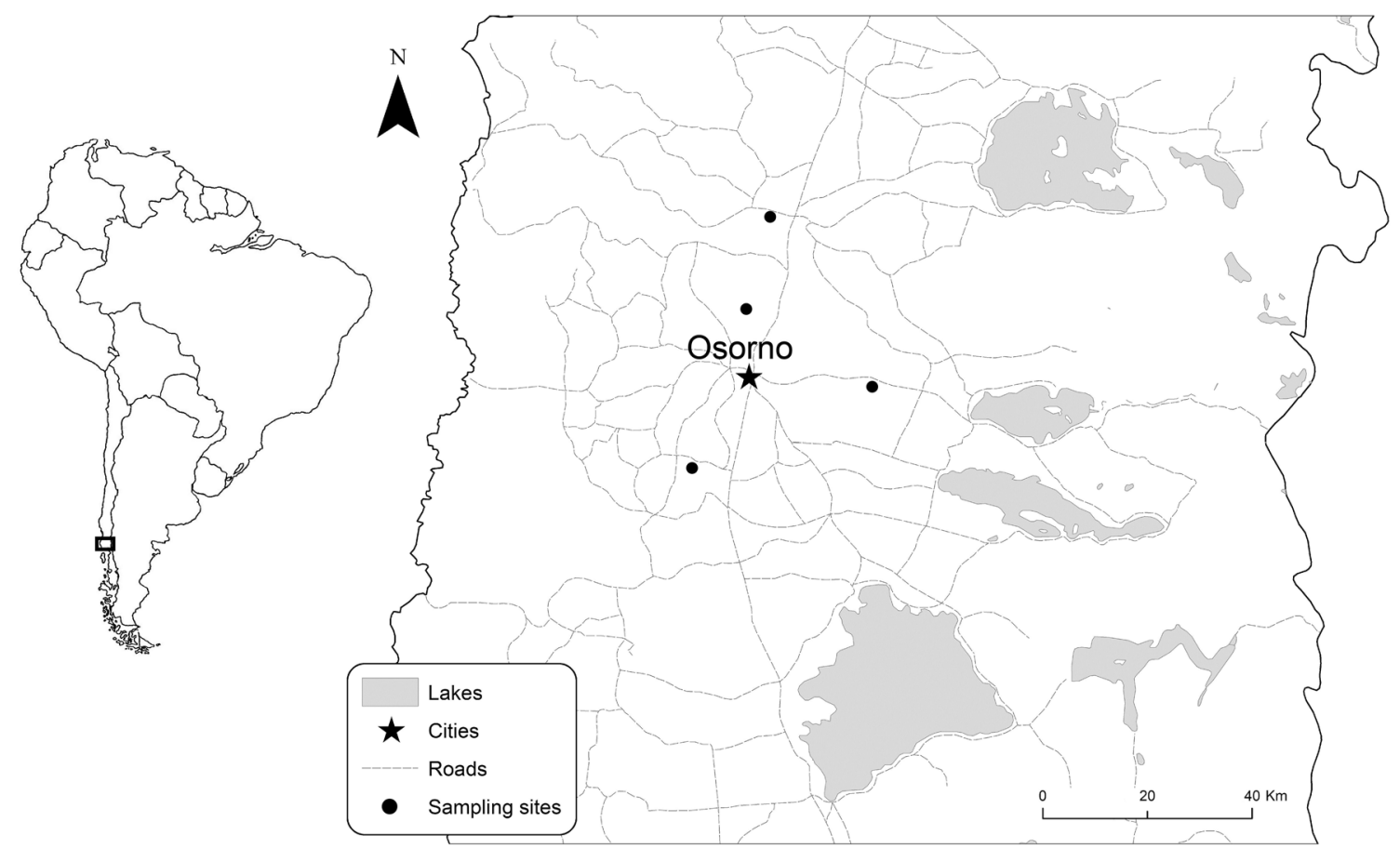

Fig. 1 Location of study area in southern Chile (inset) and locations of sampling sites near Osorno, Chile where Lophozonia tree cavities were measured

topography is generally level to rolling, with elevations ranging from around $100-400 \mathrm{~m}$ above sea level (Veblen et al. 1979).

\section{Nest cavity measurements}

We located and obtained measurements of active nest cavities of SBP in L. obliqua trees during three consecutive nesting seasons (November-January, 2008-2011). Nests were located by direct observation of SBP activities and through interviews with local residents, some of whom were former parrot nest poachers (Carneiro et al. 2013). Because non-breeding SBPs are not known to use cavities for roosting (Carneiro 2010), birds entering cavities were assumed to be breeders. Nest cavities were accessed using single-rope climbing techniques (Perry 1978; Whitacre 1981). Status and contents of each nest (eggs, chicks) were documented either by direct observation or use of a small digital camera. Because SBP breeding pairs often explore multiple cavities before selecting a nest site (Carneiro 2010), nests were considered active only if eggs or chicks were detected within the cavity. Clutch sizes for active nests were also recorded. For those cavities that were active in multiple years, we report the largest known clutch size. For some nests, it was impossible to determine accurately the exact number of eggs/ chicks, although their presence was confirmed by sight and/or sound. Cavities were inspected at least every
2-3 weeks throughout the 3-month nesting season to maximize probability of detecting and documenting nesting activities.

Heights of nest trees were measured using a clinometer and the height of cavity entrances above-groundlevel (AGL) with a nylon measuring tape. Circumference of nest trees at breast height was measured with a nylon measuring tape and used to compute diameter at breast height (DBH). Based on reported growth rates and diameter-age relationships for L. obliqua in southern Chile (see Echeverría and Lara 2004; Salas and García 2006; Salas et al. 2006), we also estimated the age of nest trees based on DBH. Nest entrance aspect (azimuth) was determined using a compass. Entrance height and width were measured using a steel measuring tape. We also measured internal diameter of cavities at entrance level in two horizontal planes-parallel and perpendicular to the entrance axis. These two measurements were then used to calculate the area of an ellipse corresponding to the horizontal area within the cavity at entrance level. Cavity depth below entrance level was measured with either a steel tape, or a small lead weight attached to a nylon line. Cavity volume below the entrance level was computed as the product of cavity depth and the internal area ellipse. For this estimate we assumed vertical uniformity in internal cavity diameters. Cavity measurements were obtained after chicks had fledged in order to minimize disturbance to nesting SBPs. 


\section{Data analyses and reporting}

We report means, standard errors, 95\% confidence intervals and ranges for 11 cavity-related variables, i.e. nest tree height, nest tree $\mathrm{DBH}$, nest tree estimated age, cavity height AGL, maximum entrance height, maximum entrance width, cavity diameter at entrance (two planes), cavity depth, internal ellipse and cavity volume. For SBP clutch sizes we report median and range for those nests in which an accurate count was obtained.

We used Rao's spacing test (Bergin 1991) to detect potential preferences in nest entrance orientation. We used Pearson product-moment correlations to test for correlations among cavity variables, given that such correlations may indicate potential external predictors of internal cavity characteristics. Because of suggested potential relationships between clutch and/or brood size and internal cavity dimensions (e.g. Karlsson and Nilsson 1977; Gustafsson and Nilsson 1985; Rendell and Robertson 1989; but see Pitts 1988; Bortolotti 1994) we also used simple linear regressions to test for relationships between SBP clutch size and the internal ellipse of cavities (a surrogate for floor area), cavity depth and cavity volume after log-transforming these cavity variables for normality (Sokal and Rohlf 1981). Because of small sample sizes, we considered tests significant at $p \leq 0.10$ to minimize Type II error (Sokal and Rohlf 1981). Statistical tests were conducted using MINITAB $^{\circledR}$ Release 13 for Windows statistical software.

\section{Results}

\section{Nest trees}

We obtained measurements from 38 different SBP nest cavities in L. obliqua trees (Table 1). Two additional nests were found, one each in Eucryphia cordifolia and L. sempervirens trees (see Carneiro et al. 2013) but not included in this study. Thus, L. obliqua provided $95 \%$ of the nest cavities used by SBP in the study area.

Using an estimated diameter increment rate of $0.4 \mathrm{~cm} /$ year (Echeverría and Lara 2004; Salas and García 2006; C. Salas pers. comm.), we estimated the average age of $L$. obliqua SBP nest trees to be approximately $336 \pm 12$ years (Table 1; Fig. 2), with the youngest being 209 years. Overall, approximately $66 \%$ of all nest trees were 250-400 years old (Fig. 2) and relicts of the original old-growth forest (Veblen et al. 1980; Díaz et al. 2005; Lara et al. 2012).

\section{Nest cavities}

Not surprisingly, cavity entrance height AGL was positively correlated with nest tree height $(r=0.379$; $p=0.02)$ and nest tree DBH $(r=0.315 ; p=0.05)$, as also reported by Cockle et al. (2011b). That is, larger
Table 1 Mean, standard error (SE), 95\% confidence interval $(\mathrm{Cl})$ and range for 11 characteristics of 38 Slender-billed Parakeet (E. leptorhynchus) nesting cavities in southern beech ( $L$. obliqua) trees in the central valley of southern Chile, 2008-2011

\begin{tabular}{|c|c|c|c|c|}
\hline Cavity feature & Mean & SE & $\mathrm{Cl}$ & Range \\
\hline Nest tree height (m) & 30.4 & 1.1 & $28.8-32.5$ & $5.0-43.5$ \\
\hline Nest tree DBH $(\mathrm{cm})$ & 134.5 & 4.7 & $125.4-144.0$ & 83.4-193.9 \\
\hline Nest tree age ${ }^{\mathrm{a}}$ (years) & 336.3 & 12.3 & $312.2-360.4$ & $209.0-485.0$ \\
\hline Cavity height ${ }^{\mathrm{b}}(\mathrm{m})$ & 12.5 & 0.9 & $10.7-14.2$ & $3.0-22.8$ \\
\hline Entrance height (cm) & 51.0 & 13.3 & $24.9-77.1$ & $28.5-400.0$ \\
\hline Entrance width (cm) & 11.5 & 0.7 & $10.2-12.8$ & $6.0-25.0$ \\
\hline Cavity diameter $\mathrm{A}^{\mathrm{C}}(\mathrm{cm})$ & 36.5 & 2.6 & $31.8-41.9$ & $12.0-73.0$ \\
\hline Cavity diameter $\mathrm{B}^{\mathrm{d}}(\mathrm{cm})$ & 39.6 & 2.4 & $34.8-44.3$ & $18.0-84.0$ \\
\hline Cavity depth (cm) & 90.3 & 24.2 & $42.9-138.5$ & $5.0-500.0$ \\
\hline Internal ellipse $\left(\mathrm{cm}^{2}\right)$ & 1239.0 & 163.0 & $919.5-1558.5$ & $170.0-4022.0$ \\
\hline Cavity volume $\mathrm{f}^{\mathrm{f}}(\mathrm{L})$ & 93.7 & 24.6 & $45.5-141.9$ & $2.9-549.5$ \\
\hline
\end{tabular}

$D B H$ diameter at breast height

a Based on Echeverría and Lara (2004), Salas and García (2006), Salas et al. (2006)

b Above ground level

c Parallel to entrance axis (front-to-rear)

d Perpendicular to entrance axis (left-to-right)

e Horizontal area within cavity at entrance level

$f$ Product of cavity depth and internal ellipse

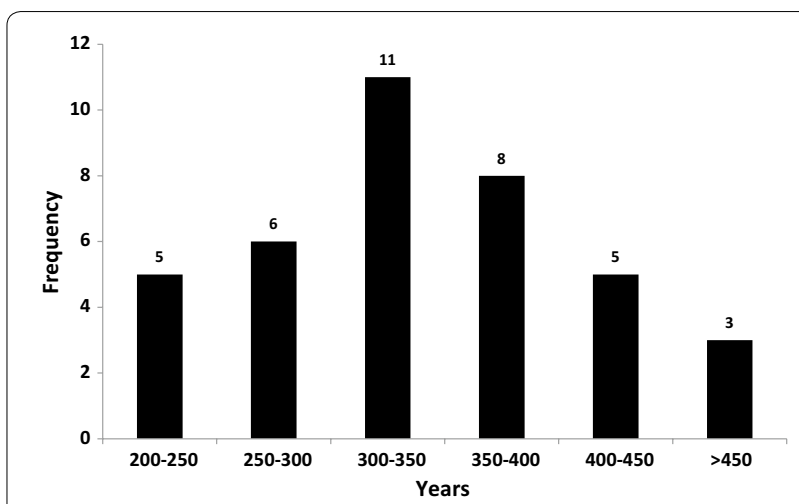

Fig. 2 Age distribution of L. obliqua trees used for nesting by E. leptorhynchus in the central valley of southern Chile, 2008-2011

and taller trees typically bore cavities that were higher above ground. All nest cavities were in the main trunk and apparently of natural origin (e.g. polypore fungal decay; see Cockle et al. 2012), as opposed to having been excavated by primary cavity users such as woodpeckers (Piciformes). Nest cavities-albeit relatively high-nevertheless tended to be located in the lower half of tree boles (Table 1), where past injuries from limb breakage or mechanical damage were oldest and fungal decay and associated cavity development likely more advanced 
(Cockle et al. 2011a, 2012). Cavity entrances also tended to be asymmetrical, with far more variation in entrance height than in width (Table 1). Nest cavities used by SBP had an average entrance width of only $11.5 \mathrm{~cm}$, as opposed to an average entrance height of $51 \mathrm{~cm}$ (Table 1). There was no significant directionality $\left(U_{38}=131.4\right.$; $p=0.27)$ in cavity entrance orientation. Entrance orientations were almost evenly distributed by cardinal direction (Fig. 3), with westerly entrances used only slightly less than other directions.

In contrast to entrance asymmetry, internal cavity diameters were more uniform, with a generally elliptical internal configuration averaging approximately $37 \mathrm{~cm} \times 40 \mathrm{~cm}$ at entrance level (Table 1; Fig. 4). Internal dimensions (depth $\times$ internal ellipse) of SBP nest cavities resulted in an average cavity volume of approximately $94 \mathrm{~L}$, with substantial variation (Table 1 ). There was no significant correlation between nest tree $\mathrm{DBH}$ and either cavity depth $(r=0.152 ; p=0.46)$ or internal ellipse $(r=0.268 ; p=0.18)$, nor between nest tree height and cavity depth $(r=-0.155 ; p=0.45)$ nor cavity entrance height AGL and cavity depth $(r=0.090 ; p=0.66)$. In other words, there were no reliable external predictors of cavity depth or volume. However, there was a marginally significant negative correlation $(r=-0.321 ; p=0.10)$ between cavity entrance height AGL and internal ellipse, suggesting that higher cavities have slightly smaller internal diameters, as would be expected due to typical vertical tapering of Lophozonia trunks (Veblen et al. 1980; Bunnell et al. 2002; Salas and García 2006). If so, this could mean that we may have slightly underestimated floor area (from entrance internal ellipse) and cavity volume, especially for the deepest cavities with potentially more vertical internal taper.

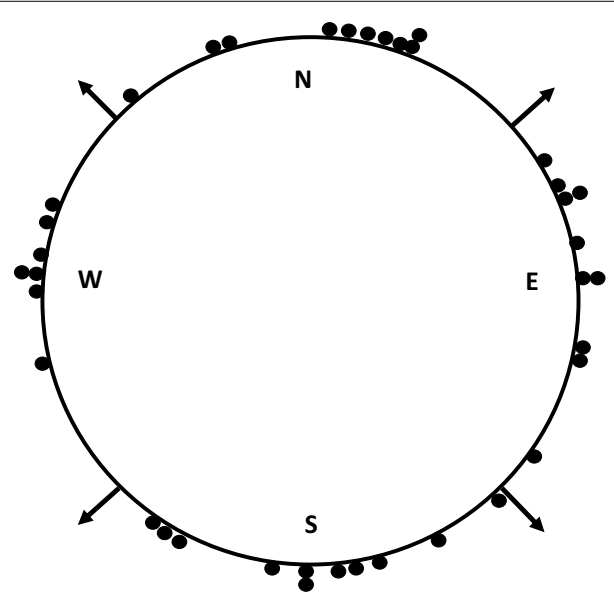

Fig. 3 Entrance orientations of nest cavities in L. obliqua trees used by E. leptorhynchus in the central valley of southern Chile, 2008-2011

\section{Clutch size}

Clutch sizes $(n=26)$ for SBP ranged from two to nine, with a median (and mode) of five (Fig. 5), with broods of up to seven well-developed nestlings observed (Fig. 4). There was no significant relationship between clutch size and cavity internal ellipse $\left(r^{2}=0.03 ; F_{1,19}=0.51\right.$; $p=0.48)$, although a slightly stronger-albeit non-significant-relation was detected between clutch size and cavity depth $\left(r^{2}=0.08 ; F_{1,18}=1.48 ; p=0.24\right)$. However, a marginally significant positive relationship was detected between clutch size and cavity volume $\left(r^{2}=0.14\right.$; $\left.F_{1,18}=2.91 ; p=0.10\right)$.

\section{Discussion}

\section{Nest trees used by SBP and cavity entrance}

In this study, SBP nested almost exclusively (95\%) in cavities of mature southern beech (L. obliqua) trees. Snyder et al. (1987) reported similar findings for Puerto Rican Parrots (Amazona vittata) nesting in montane rainforests of the Luquillo Mountains, where palo colorado trees (Cyrilla racemiflora) accounted for $96 \%$ of known nest cavities. In the Pantanal region of Brazil, cavities in Panama trees (Sterculia apetala) also accounted for nearly $86 \%$ of Hyacinth Macaw (Anodorhynchus hyacinthus) nests (Pinho and Nogueira 2003). In New Zealand, a single species (Metrosideros excelsa) provided $67 \%$ of the tree-cavity nests used by Red-crowned Parakeets (Cyanoramphus novaezelandiae; Ortiz-Catedral and Brunton 2009).

Nest trees used by SBP were also relatively large (Table 1) compared to those used by psittacines elsewhere (see Rivera et al. 2011; Renton et al. 2015). For example, Díaz and Kitzberger (2012) reported that nest cavities of the congeneric Austral Parakeet in Argentina were found in Nothofagus pumilio trees averaging $61 \mathrm{~cm}$ $\mathrm{DBH}$, less than half the size of those reported in this study. According to Renton et al. (2015), most (ca. 80\%) psittacines nest in trees $<125 \mathrm{~cm} \mathrm{DBH}$, compared to the mean of $134 \mathrm{~cm}$ used by SBP (Table 1 ).

However, our findings regarding cavity entrance height (Table 1) are consistent with those of Renton et al. (2015), who reported that $60 \%$ of psittacines use cavities with entrances >9 m AGL. Nilsson (1984) and Renton et al. (2015) both assert that selection of nest sites higher up in trees is an adaptive response to predation. As example, Cockle et al. (2015) reported greater nest survival in higher cavities that provided greater protection from terrestrial mammals, as did Sanz (2008) for nests of Yellowshouldered Parrots (Amazona barbadensis) in Venezuela. Indeed, in our study region there are several ground and/ or semi-scansorial potential predators of SBP (e.g. Pseudalopex griseus, Leopardus guigna, and exotic Felis catus and Neovison vison) that may be more effectively avoided by nesting in higher cavities. 

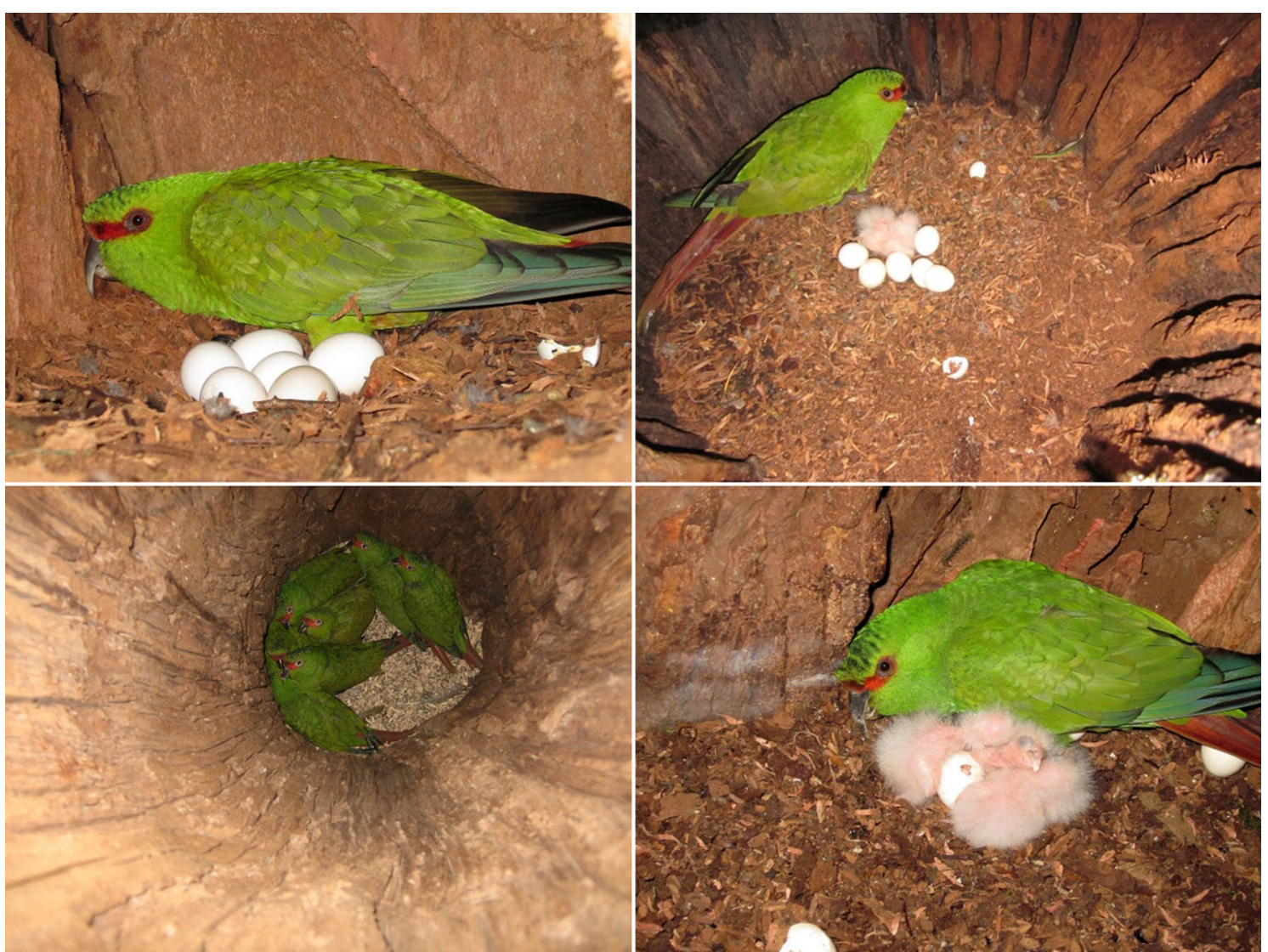

Fig. 4 Interiors of E. leptorhynchus nest cavities in L. obliqua trees, central valley of southern Chile, 2008-2011. Note brood of seven nestlings near fledging age in lower left image (photos by JEJ)

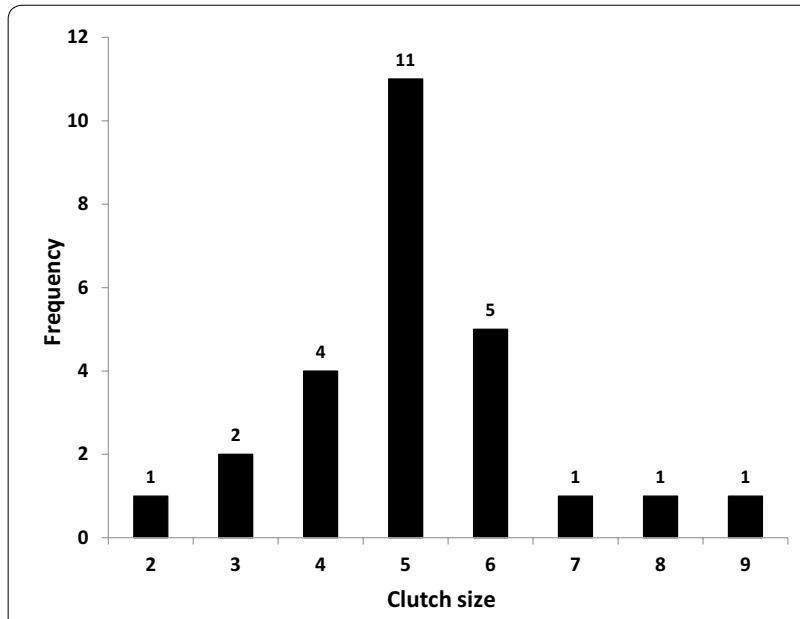

Fig. 5 Clutch sizes of E. leptorhynchus nesting in L. obliqua cavities in the central valley of southern Chile, 2008-2011

Entrance dimensions of SBP nest cavities were similar to those used by Tucuman Parrots (Amazona tucumana) in old-growth forests in Argentina (Rivera et al. 2011).
Indeed, Rivera et al. (2011) also reported a general trend of asymmetry in nest cavity entrances used by 10 other Amazona spp., with all exhibiting far less variation in entrance width than height. Based on data from 59 parrot species, Renton et al. (2015) also found that the diameter of the cavity entrance was significantly related to parrot body size. Interestingly, applying the Renton et al. (2015) entrance diameter/body mass equation $(y=0.01 x+10.14)$ to the SBP $(290 \mathrm{~g})$ predicts a cavity entrance diameter of approximately $13 \mathrm{~cm}$, in close accordance with our findings (Table 1). In general, parrots tend to use cavity entrances with widths just large enough for them to enter, yet small enough to deter larger competitors or predators (Brightsmith 2005a; Renton et al. 2015).

\section{Size and orientation of nest cavities}

Internal diameters of SBP nest cavities in this study were somewhat larger than those of similar-sized parrots reported by Renton et al. (2015), who found that cavities with internal diameters $\geq 40 \mathrm{~cm}$ were typically used by larger-bodied macaws and cockatoos, as also reported 
by Parra-Martínez et al. (2015). Similar to findings of Peña-Foxon et al. (2011), nest cavity substrate consisted primarily of decomposed dry wood fragments sloughed off from interior walls, mixed with a few scattered SBP body feathers (Fig. 4). Average depth of SBP nest cavities $(90 \mathrm{~cm})$ was comparable to those used by other psittacines (Rivera et al. 2011; Renton et al. 2015), most of which (86\%) use cavities with a mean depth $\geq 50 \mathrm{~cm}$, with over a third using cavities $>90 \mathrm{~cm}$ deep. As with cavity entrance height, deeper cavities also tend to provide greater protection from nest competitors and predators (Martin et al. 2004; Cockle et al. 2011b). For example, deeper cavities provide greater protection to Puerto Rican Parrots from nest predation and usurpation by Pearly-eyed Thrashers (Margarops fuscatus; Snyder et al. 1987; White et al. 2005). In Australia, Saunders et al. (2014) found that Carnaby's Cockatoos (Calyptorhynchus latirostris) that selected nesting cavities $<40 \mathrm{~cm}$ deep were less successful than those using cavities $>100 \mathrm{~cm}$ in depth. Indeed, predation (and its avoidance) is considered to have had a major effect on the evolution of avian nesting behavior, especially that of cavity-nesters (Nilsson 1984; Martin 1993a; Brightsmith 2005a).

Our findings contrast with those of several prior studies of psittacine nest sites (e.g. White et al. 2006; Dias 2011; Díaz and Kitzberger 2012), in which birds showed distinct preferences in entrance orientations. For example, White et al. (2006) found a preference by Puerto Rican Parrots for southwesterly entrance orientations providing protection from prevailing winds and rain, as did Snyder et al. (1987), who further reported nonrandom orientations of Hispaniolan Parrot (Amazona ventralis) nests in the Dominican Republic. Dias (2011) also reported a significant preference for northeasterly cavity entrances by Yellow-faced Parrots (Alipiopsitta xanthops) in Brazil, but did not posit any reasons for such. Moreover, Díaz and Kitzberger (2012) found a distinct avoidance of westerly-facing nest cavities by the congeneric Austral Parakeet in neighboring Argentina, ostensibly to lessen exposure to dominant winds and storms from the nearby Andes Mountains. However, the study area of Díaz and Kitzberger (2012) was on the opposite side (i.e. east) of the Andes from our study area. In our study area, a lack of strong prevailing winds or significant storm events during the SBP nesting season (DMC 2001) likely reduces selective pressure on cavity entrance orientation. Thus, SBP apparently do not exhibit selectivity for this cavity feature. In the agricultural "wheatbelt" of Western Australia, Saunders et al. (1982) reported similar findings for cavity-nesting Galahs (Cacatua roseicapilla), Corellas (Cacatua pastinator), and Red-tailed Black Cockatoos (Calyptorhynchus magnificus).

\section{Clutch size and factors affecting it}

Clutch and brood sizes of SBP were extraordinarily large. Peña-Foxon et al. (2011) also reported clutch sizes $(n=2)$ of six and ten for SBP nesting in Nothofagus nitida trees on Chiloé Island, approximately $140 \mathrm{~km}$ south of our study area. Moreover, Díaz and Kitzberger (2012) documented clutch sizes of 3-10 for the Austral Parakeet nesting in N. pumilio cavities in Argentina. Such large clutches for psittacines of this size are unusual, as they are normally associated with parrots less than half their size (see Beissinger and Waltman 1991; Masello and Quillfeldt 2002; Ortiz-Catedral and Brunton 2009). By comparison, psittacines approximately the same size as the SBP (ca. 280-300 g) typically lay 2-4 eggs (see Snyder et al. 1987; Rinke 1989; Enkerlin-Hoeflich 1995; Masello and Quillfeldt 2002). Indeed, the body mass/clutch size allometric curve of Masello and Quillfeldt (2002) predicts a clutch size of 3-4 for the SBP.

The observed relationship between clutch size and cavity volume suggests that the combination of two internal characteristics (depth $\times$ internal diameter) may affect nest productivity (via clutch size) more than either variable separately. Given evidence that internal diameters at entrance level may underestimate floor areas of deeper cavities (see "Results" section), this might explain such a counterintuitive pattern, since the actual effect of cavity floor area on clutch size would also have been underestimated in this case; hence the observed interaction (and increased effect) of entrance internal ellipse and depth. Indeed, in a study of several cavitynesting passerine species, Van Balen (1984) reported that clutch size steadily increased with cavity volume and with cavity floor areas up to around $150 \mathrm{~cm}^{2}$, but found a weaker relationship in larger (e.g. $>300 \mathrm{~cm}^{2}$ ) cavities. Alatalo et al. (1988) reported similar findings for Pied Flycatchers (Ficedula hypoleuca), as did Rendell and Robertson (1989) for Tree Swallows (Tachycineta bicolor). In our case, some caveats to this assertion include our small sample sizes and high variability (Table 1), which also may have reduced the likelihood of detecting the effect of the internal area of a cavity on clutch size, if any (see Purcell et al. 1997). Moreover, Karlsson and Nilsson (1977) reported that clutch sizes and productivity of "larger" species showed far less response to changes in cavity size. Thus, these specific findings (i.e. SBP clutch size/cavity dimensions) remain inconclusive, albeit suggestive of areas for future investigation into SBP nesting ecology.

If our findings on the effects of cavity dimensions per se on SBP clutch size are inconclusive, what other hypotheses might explain observed patterns and extraordinarily large clutches? According to the limited breeding opportunities hypothesis for avian clutch size (Beissinger 
and Waltman 1991; Martin 1993b; Beissinger 1996), limitations in either the number or availability of adequate nest sites should favor an increase in clutch size, in order to maximize returns on energy investment (and hence increase fitness) of reduced nesting opportunities. If so, then populations without nest site limitations should have smaller clutches than those with limited availability of cavities. However, Díaz and Kitzberger (2012) found that nesting by the congeneric Austral Parakeet in intact old-growth forests was apparently not limited by cavity availability, yet clutch sizes equaled or exceeded those of SBP in this study. Other researchers (e.g. Brightsmith 2005b; Wesołowski 2007; Rivera et al. 2011) have also reported that secondary cavity-nesters do not face cavity limitations in "primeval" or intact old-growth forests. However, over the past century the area and distribution of old-growth Lophozonia forests have been reduced by at least $98 \%$ throughout the central valley of southern Chile (Salas et al. 2006; Echeverría et al. 2007). Although we have no quantitative data on current Lophozonia cavity availability within the central valley, it is intuitively logical that such a sweeping landscape-level conversion of old-growth forests to agricultural production has resulted in a concomitant reduction in Lophozonia cavity availability for SBP across the region. Yet, SBP clutch sizes were no larger than those of its closely-related congeneric species nesting in intact old-growth forests. Accordingly, the predictions of the limited breeding opportunities hypothesis relative to clutch size for this species are not consistent with our findings.

Instead, we hypothesize that the relationship between SBP clutch size and Lophozonia cavities constitutes more than a facultative response to specific characteristics and availability of existing cavities (i.e. limited breeding opportunities) and may instead represent an evolutionary adaptation to the latitudinal range of this species. The genus Enicognathus, comprised of the SBP and its congeneric Austral Parakeet, occupies an overall geographic range between $34^{\circ} \mathrm{S}$ and $56^{\circ} \mathrm{S}$ in the Patagonia region of Chile and Argentina (Ridgely et al. 2005; Díaz and Kitzberger 2012; JEJ unpublished data). The Lakes Region of southern Chile (location of our study area) lies at approximately $40^{\circ} \mathrm{S}-42^{\circ} \mathrm{S}$. At these higher latitudes, night-time temperatures during the SBP nesting season (November-January) often decline to $2-5{ }^{\circ} \mathrm{C}$ (DMC 2001). Peña-Foxon et al. (2011) reported that SBP nestlings exhibited two successive downs prior to feather development, with the second down being particularly dense and attributed this to adaptation to colder temperatures. If so, large broods may be an additional thermoregulatory adaptation, as the increased mass of additional nestlings may more effectively retain heat, especially during recurrent night-time low temperatures. Although nesting adults roost inside cavities with their nestlings, the increased mass of larger family groups may provide thermoregulatory benefits to all members. Additionally, increased clutch size may also provide increased insurance against incubation losses (Renton and Salinas-Melgoza 2004; Olah et al. 2014), when the effects of an adverse nest microclimate may be more manifest (Webb 1987; Beissinger et al. 2005). Indeed, during this study we observed that although broods were relatively large (i.e. 3-7), in some nests several eggs failed to hatch, for unknown reasons. Peña-Foxon et al. (2011) reported similar observations for SBP nests on northeastern Chiloé Island $\left(41^{\circ} \mathrm{S}, 73^{\circ} \mathrm{W}\right)$. The factors affecting incubation and avian embryonic development are complex (see Bucher 1983; Wiebe 2001; Shoji et al. 2015) and while several studies have found speciesspecific variations in thermal tolerances (e.g. Williams and Ricklefs 1984; Booth 1987; Sockman and Schwabl 1998), optimal incubation conditions for SBP in natural cavities remain unknown. Although increased clutch size has been shown to increase energy costs to incubating females (Haftorn and Reinertsen 1985; Moreno and Carlson 1989; Reid et al. 2000), the potential gains in fitness accrued via larger broods may ultimately offset any such incubation costs for SBP (Charnov and Krebs 1973; Smith and Fretwell 1974; Brockelman 1975).

\section{Threats to SBP habitat}

The vast majority of old-growth Lophozonia trees have been lost to agricultural conversion throughout the central valley (Echeverría et al. 2006, 2007; Salas et al. 2006). The relict, scattered mature trees ("pellines") that remain have apparently allowed SBP to adapt successfully-at least temporarily-to what is effectively a wholesale loss and fragmentation of their ancestral habitat. We emphasize "temporarily", because the apparent lack of regeneration and the more recent replacement of pellines in the region by exotic Monterrey pines (Pinus radiata) and Eucalyptus spp. (Carneiro 2010; Lara et al. 2012), coupled with the now advanced age of existing nest-cavity pellines (Fig. 2), portends a yet further and dramatic future decline in this resource with ominous implications for SBP, as also predicted by Ibarra and Martin (2015) for the congeneric Austral Parakeet. Even without natural attrition, pellines are also being rapidly lost to felling for fence posts, firewood and further agricultural intensification (Fig. 6; see also Carneiro et al. 2012). In Australia, Saunders et al. (2014) reported a strikingly similar situation with Carnaby's Cockatoo, in which cumulative loss and lack of replacement of large nest trees is predicted to result in the loss of $70 \%$ of all nest sites for the species over the next 100 years. A similar cumulative loss of Lophozonia pellines in the central valley of southern Chile could potentially result in loss of up to $95 \%$ of SBP nesting sites, based on current nesting behavior. These 


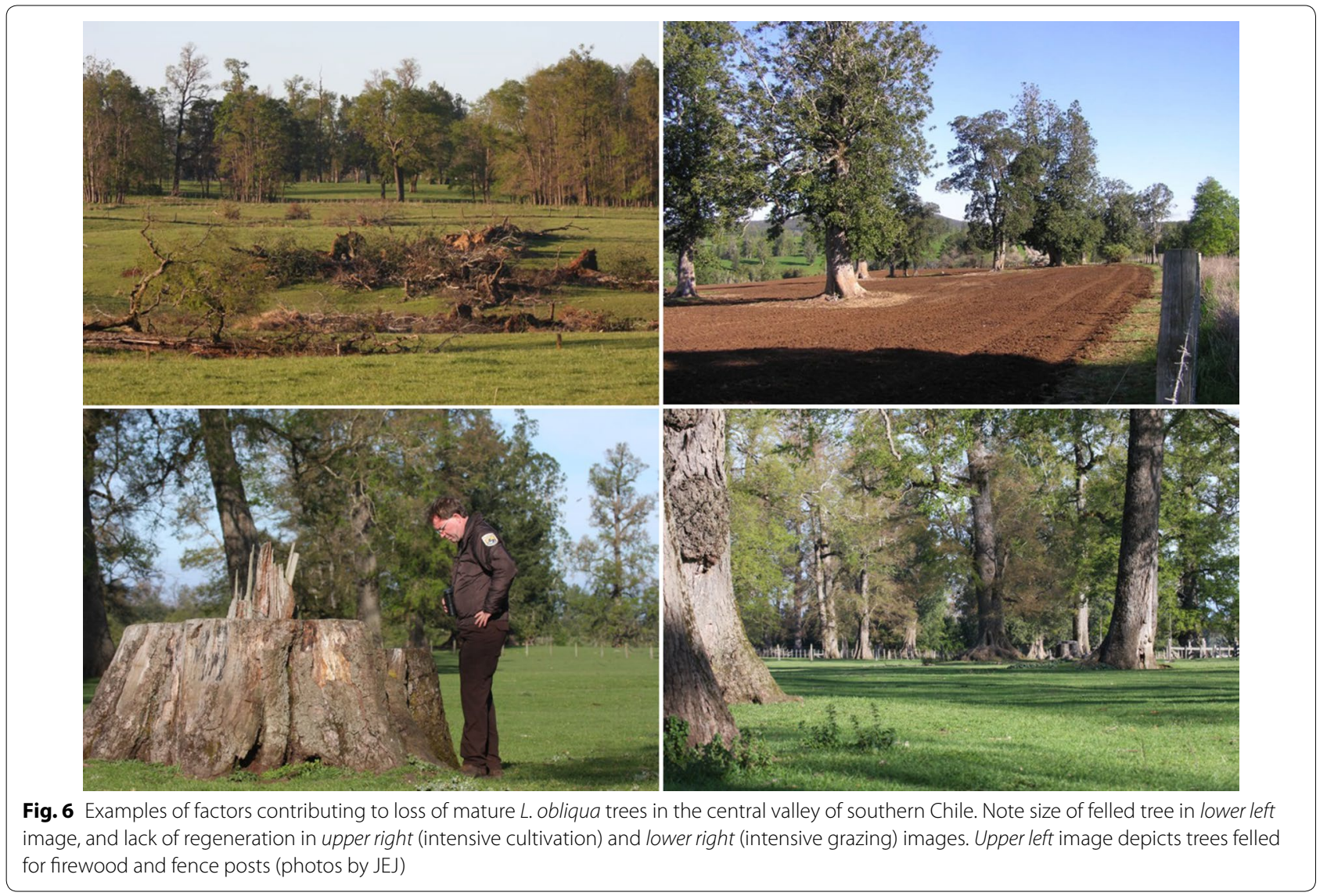

situations are not merely isolated events, as large old cavity-bearing trees are in rapid decline globally (Gibbons et al. 2008; Lindenmayer et al. 2012, 2014), jeopardizing their unique ecological role in maintaining ecosystem functions and attendant biodiversity (Manning et al. 2006; Manning and Lindenmayer 2009; Ibarra and Martin 2015). For secondary cavity nesters such as the SBP, the loss of suitable nest cavities can have severe consequences. For instance, due to widespread deforestation during the past century, the Puerto Rican Parrot was relegated to nesting in unsuitable cavities, resulting in the near demise of the species (Snyder et al. 1987; White et al. 2014). In this case, intensive nest cavity management and substitution with artificial cavities narrowly averted species extinction (Snyder et al. 1987; White et al. 2005), but to replicate such efforts at the scale necessary to ensure regional SBP survival would be logistically complicated, exceedingly time-consuming, and prohibitively costly.

\section{Conclusions}

In the central valley of southern Chile, mature Lophozonia trees provide typically large, deep and spacious nest cavities for Slender-billed Parakeets. Use of Lophozonia cavities for nesting appears highly adaptive for
SBP; as such cavities allow successful rearing of large broods, thereby maximizing productivity and fitness. The high use of not only L. obliqua, but also N. pumilio and $N$. nitida by nesting Enicognathus spp. in the Patagonia region suggests a keystone role of southern beech (i.e. Nothofagaceae) in the regional ecology of Enicognathus. Nearly $91 \%$ of all documented Enicognathus spp. nest cavities have occurred in large, mature Lophozonia or Nothofagus spp. trees throughout the Patagonian landscape. These genera may be more prone to fungal heart rot and thus, offer more natural cavities than other tree species. Furthermore, frequent use of old-growth Lophozonia and Nothofagus spp. trees as food sources by Enicognathus suggests the genus Enicognathus an oldgrowth specialist. Clearly, the ecological importance of this unique forest resource for these parrots should not be underestimated.

Finally, while we recognize and acknowledge the speculative nature of some of our hypotheses, given the current paucity of ecological data on the SBP, we believe such speculation is both warranted and useful in this instance for elucidating potentially fertile areas for future research. Indeed, identifying and addressing current species-specific ecological uncertainties is a logical and 
necessary step towards strengthening the scientific basis for effective conservation strategies aimed at preventing or reducing future SBP population declines. Moreover, further study of SBP ecology in the few remaining undisturbed and/or lesser disturbed forests outside the central valley may also provide additional validation or refutation of our specific findings and hypotheses.

\section{Conservation implications}

If the SBP is to persist in the central valley of southern Chile, several steps must be taken in the near term to ensure the continued availability of suitable nest cavities (see Manning and Lindenmayer 2009; Ibarra and Martin 2015). Foremost among these is the conservation of existing pellines with characteristics consistent with those used by SBP (see Carneiro et al. 2013; this study). This will require extensive surveys to determine current numbers and distribution of such trees in the region and to prioritize specific areas for conservation efforts, as also suggested by Lindenmayer et al. (2014) for similar landscapes globally. Secondly, given that Lophozonia trees apparently need at least 200 years to produce cavities suitable for SBP (Fig. 2), conservation programs should also include those trees within the 150-200 year age class (i.e. $60-80 \mathrm{~cm}$ DBH). In Australia, similar findings were reported by Gibbons and Lindenmayer (2002), who found that large cavities were rare in trees $<220$ years old. Upon reaching their cavity-producing age (ca. more than 200 years), pellines may potentially provide useable SBP nest cavities for up to two centuries, based on ages of nest trees in this study (Fig. 2). Finally, promoting effective regeneration of new southern beech trees at appropriate sites should also be fostered (Veblen et al. 1979; Lindenmayer et al. 2014), since current intensive land use practices severely inhibit natural Lophozonia regeneration (see Fig. 6). In such cases, Manning et al. (2006) proposed the technique of "micro-restoration", by which regeneration is facilitated by selectively fencing small ( $<30 \mathrm{~m}$ radius) areas around existing large trees, or groups of large trees. Given that virtually all such trees are on private land, this will also require creative and effective conservation agreements with landowners, coupled with systematic and continuous public environmental education on the ecological value of pellines. This is not a straightforward affair; many farmers in the region consider the SBP to be a crop pest due to its foraging on germinating grains. During informal conversations with a number of these farmers, most admitted that crop losses to SBP were inconsequential, but there were yet others for whom no losses at all were acceptable and conservation of pellines to benefit the SBP would be unlikely to garner support from those of such mind. Accordingly, effective conservation of pellines would also likely require some type of enforceable codified measures by local and/or national policy-makers.

At a broader sociological and temporal scale, promoting the overall ecological importance of pellines in the southern Chilean landscape may likely be the most effective means of engendering local appreciation of -and support for-protection of these old-growth forest relicts. Such trees have been termed "keystone structures" due to the wide variety of organisms and ecological processes with which they are intricately associated (e.g. Tews et al. 2004; Manning et al. 2006; Lindenmayer et al. 2014). Indeed, during our study we also documented use of pellines for nesting-in cavities or branches-by several other avian species (e.g. Jiménez and White 2011), as well as use of ground-level cavities for denning by Patagonian gray foxes (P. griseus). Thus, conservation and perpetuation of cavity-bearing pellines would provide long-term benefits not only to Slender-billed Parakeets, but also to a broader community of vertebrate species in southern Chile.

\section{Authors' contributions}

THW was responsible for data analyses and writing the manuscript, as well as assisting with planning and conducting the research, including assisting with fieldwork. JEJ was responsible for leading and directing all field data collection activities, collaborating with international donors and volunteers, managing the project budget and all associated logistical details and permit requirements in Chile. Both authors read and approved the final manuscript.

\section{Author details \\ ${ }^{1}$ Puerto Rican Parrot Recovery Program, United States Fish and Wildlife Service, Box 1600, Rio Grande, PR 00745, USA. ${ }^{2}$ Sub-Antarctic Biocultural Conservation Program, Department of Biological Sciences, University of North Texas, Denton, TX 76201, USA. ${ }^{3}$ Sub-Antarctic Biocultural Conservation Program, Department of Philosophy and Religion, University of North Texas, Denton, TX 76201, USA. ${ }^{4}$ Omora Etnobotanical Park, Universidad de Magallanes, Puerto Williams, Chile.}

\section{Acknowledgements}

We are grateful to the Laboratorio de Vida Silvestre at Universidad de Los Lagos, the United States Fish and Wildlife Service-Puerto Rican Parrot Recovery Program, Parrots International, Amigos de las Aves_USA, Canadian Parrot Society, International Conure Association, Parrot Conservation Fund, and Tony Pittman for funding and/or logistical support of this research. We also thank the administration of INIA-Remehue and the many private landowners who allowed us access to their properties. Numerous students and volunteers also assisted with nest monitoring and cavity measurements, especially Samuel Alywin, Ana Carneiro, Magdalena Contreras, Gemma Ffrench, Claire Foster, Daniel Gonzalez, Gemma Harding, Mauricio Ojeda, Nelson Ojeda, Suzan Payne, Nicole Pueschel, Marie Stafford and Mark Stafford. Two anonymous reviewers provided valuable comments that helped improve a prior version of this article. The findings and conclusions are those of the authors and do not necessarily represent the views of the US Fish and Wildlife Service. Use of trade names in this article does not imply endorsement by the United States Government.

\section{Competing interests}

Both authors declare that they have no competing interests.

\section{Availability of data and materials}

The datasets used and/or analyzed during the current study are available from the corresponding author on reasonable request.

Received: 18 July 2016 Accepted: 11 January 2017

Published online: 06 February 2017 


\section{References}

Alatalo RV, Carlson A, Lundberg A. Nest cavity size and clutch size of Pied Flycatchers Ficedula hypoleuca breeding in natural tree-holes. Orn Scand. 1988;19:317-9.

Beissinger SR, Cook MI, Arendt WJ. The shelf life of bird eggs: testing egg viability using a tropical climate gradient. Ecology. 2005;86:2164-75.

Beissinger SR, Waltman JR. Extraordinary clutch size and hatching asynchrony of a Neotropical parrot. Auk. 1991;108:863-71.

Beissinger SR. On the limited breeding opportunities hypothesis for avian clutch size. Am Nat. 1996;147:655-8.

Bergin TM. A comparison of goodness-of-fit tests for analysis of nest orientation in western kingbirds (Tyrannus verticalis). Condor. 1991;93:164-71.

Booth DT. Effect of temperature on development of Mallee Fowl Leipoa ocellata eggs. Physiol Zool. 1987;60:437-45.

Bortolotti GR. Effect of nest-box size on nest-site preference and reproduction in American Kestrels. J Raptor Res. 1994:28:127-33.

Brightsmith DJ. Competition, predation and nest niche shifts among tropical cavity nesters: phylogeny and natural history evolution of parrots (Psittaciformes) and trogons (Trogoniformes). J Avian Biol. 2005a;36:64-73.

Brightsmith DJ. Competition, predation and nest niche shifts among tropical cavity nesters: ecological evidence. J Avian Biol. 2005b;36:74-83.

Brockelman WY. Competition, the fitness of offspring, and optimal clutch size. Am Nat. 1975;109:677-99.

Bucher TL. Parrot eggs, embryos, and nestlings: patterns and energetics of growth and development. Physiol Zool. 1983;56:465-83.

Bunnell FL, Wind E, Boyland M, Houde I. Diameters and heights of trees with cavities: their implications to management. Tech. Rep. PSW-GTR-181, USDA For. Serv. Gen. 2002

Bunnell FL. Sustaining cavity-using species: patterns of cavity use and implications to forest management. ISRN For. 2013. doi:10.1155/2013/457698.

Carneiro AP, Jiménez JE, Soto M, White TH Jr. Distribution of Slender-billed Parakeets (Enicognathus leptorhynchus) in a fragmented agricultural landscape of southern Chile. Ornitol Neotrop. 2012;23:201-13.

Carneiro AP, Jiménez JE, Vergara PM, White TH Jr. Nest-site selection by the Slender-billed Parakeet (Enicognathus leptorhynchus) in a Chilean agricultural-forest mosaic. J Field Ornithol. 2013;84:13-22.

Carneiro AP, Jiménez JE, White TH Jr. Post-fledging habitat selection by the Slender-billed Parakeet in a fragmented agricultural landscape of southern Chile. Condor. 2011;114:166-72.

Carneiro AP. Uso espacial de paisajes fragmentados por el Choroy (Enicognathus leptorhynchus) en el sur de Chile. M.S. thesis, Universidad de Los Lagos, Osorno, Chile. 2010.

Charnov EL, Krebs JR. On clutch-size and fitness. Ibis. 1973;116:217-9.

Cockle KL, Bodrati A, Lammertink M, Martin K. Cavity characteristics, but not habitat, influence nest survival of cavity-nesting birds along a gradient of human impact in the subtropical Atlantic forest. Biol Conserv. 2015;184:193-200.

Cockle KL, Martin K, Drever MC. Supply of tree-holes limits density of cavitynesting birds in primary and logged subtropical Atlantic forest. Biol Conserv. 2010;143:2851-7.

Cockle KL, Martin K, Robledo G. Linking fungi, trees, and hole-using birds in a Neotropical tree-cavity network: pathways of cavity production and implications for conservation. For Ecol Manage. 2012;264:210-9.

Cockle KL, Martin K, Wesołowski T. Woodpeckers, decay, and the future of cavity-nesting vertebrate communities worldwide. Front Ecol Environ. 2011a;9:377-82

Cockle KL, Martin K, Wiebe K. Selection of nest trees by cavity-nesting birds in the Neotropical Atlantic Forest. Biotropica. 2011b;43:228-36.

Cornelius C, Cockle K, Politi N, Berkunsky I, Sandoval L, Ojeda V, Rivera L, Hunter M Jr, Martin K. Cavity-nesting birds in Neotropical forests: cavities as a potentially limiting resource. Ornitol Neotrop. 2008;19(Suppl.):253-68.

Dias RI. Nesting biology of the Yellow-faced Parrot (Alipiopsitta xanthops), a species without nest-site fidelity: an indication of high cavity availability? Emu. 2011;111:217-21.

Díaz IA, Armesto JJ, Reid S, Sieving KE, Willson MF. Linking forest structure and composition: avian diversity in successional forests of Chiloé Island, Chile. Biol Conserv. 2005;123:91-101.

Díaz S, Kitzberger T. High Nothofagus flower consumption and pollen emptying in the South American Austral Parakeet (Enicognathus ferrugineus). Austral Ecol. 2006:31:759-66.
Díaz S, Kitzberger T. Nest habitat selection by the Austral Parakeet in northwest Patagonia. Austral Ecol. 2012;38:268-78.

Dirección Meteorológica de Chile (DMC). Estadística Climatología:Tomo II. Santiago: Gobierno de Chile; 2001.

Echeverría C, Lara A. Growth patterns of secondary Nothofagus obliqua-N. alpina forests in southern Chile. For Ecol Manage. 2004;195:29-43.

Echeverría C, Coomes DA, Newton AC, Salas J, Rey JM, Lara A. Rapid fragmentation and deforestation of Chilean temperate forests. Biol Conserv. 2006:130:481-94.

Echeverría C, Newton AC, Lara A, Benayas MR, Coomes DA. Impacts of forest fragmentation on species composition and forest structure in the temperate landscapes of southern Chile. Glob Ecol Biogeogr. 2007;16:426-39.

Echeverría C, Newton AC, Nahuelhual L, Coomes DA, Benayas JM. How landscapes change: integration of spatial patterns and human processes in temperate landscapes of southern Chile. Appl Geogr. 2012;32:822-31.

Edworthy AB, Martin K. Persistence of tree cavities used by cavity-nesting vertebrates declines in harvested forests. J Wildl Manage. 2013;77:770-6.

Edworthy AB, Wiebe KL, Martin K. Survival analysis of a critical resource: patterns of tree cavity longevity. Ecol Appl. 2012;22:1733-42.

Enkerlin-Hoeflich EC. Comparative ecology and reproductive biology of three species of Amazona parrots in northeastern Mexico. Dissertation, Texas A\&M University, College Station, TX USA. 1995.

Escanilla VR. Patrones espacio-temporales de la vegetación nativa en cuatro paisajes locales de la depresión intermedia de la Provincia de Osorno, Región de Los Lagos. Undergraduate thesis, Engineering in Natural Resources, Universidad de Chile, Santiago. 2012.

Gibbons P, Lindenmayer DB. Tree hollows and wildlife conservation in Australia. Collingwood: CSIRO; 2002.

Gibbons P, Lindenmayer DB, Fischer J, Manning AD, Weinberg A, Seddon J, Ryan P, Barrett $G$. The future of scattered trees in agricultural landscapes. Conserv Biol. 2008;22:1309-19.

Gustafsson L, Nilsson SG. Clutch size and breeding success of Pied and Collared Flycatchers Ficedula spp. in nest-boxes of different sizes. Ibis. 1985;127:380-5.

Haftorn S, Reinertsen RE. The effect of temperature and clutch size on the energetic cost of incubation in a free-living Blue Tit (Parus caeruleus). Auk. 1985; 102:470-8.

Heenan PB, Smissen RD. Revised circumscription of Nothofagus and recognition of the segregate genera Fuscospora, Lophozonia, and Trisyngyne (Nothofagaceae). Phytotaxa. 2013;146:1-31.

Ibarra JT, Martin K. Biotic homogenization: loss of avian functional richness and habitat specialists in disturbed Andean temperate forests. Biol Conserv. 2015;192:418-27.

IUCN. Enicognathus leptorhynchus. The IUCN red list of threatened species. Version 2015.2. 2015. www.iucnredlist.org. Accessed 01 Sep 2015.

Jiménez JE, White TH Jr. Use of tree cavities for nesting by Speckled Teal (Anas flavirostris) in southern Chile: potential competition with Slender-billed Parakeets (Enicognathus leptorhynchus). Ornitol Neotrop. 2011;22:465-9.

Karlsson J, Nilsson SG. The influence of nest-box area on clutch size in some hole-nesting passerines. Ibis. 1977;119:207-11.

Kottek M, Grieser J, Beck C, Rudolf B, Rubel R. World map of the Köppen-Geiger climate classification updated. Meteor Z. 2006;15:259-63.

Lara A, Solari ME, Del Rosario PrietoM, Peña MP. Reconstrucción de la cobertura de la vegetación y uso del suelo hacia 1550 y sus cambios a 2007 en la ecorregión de los bosques valdivianos Iluviosos de Chile

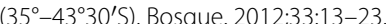

Lindenmayer DB, Laurance WF, Franklin JF, Likens GE, Banks SC, Blanchard W, Gibbons P, Ikin K, Blair D, McBurney L, Manning AD, Stein JAR. New policies for old trees: averting a global crisis in a keystone ecological structure. Conserv Lett. 2014;7:61-9.

Lindenmayer DB, Laurance WF, Franklin JF. Global decline in large old trees. Science. 2012:338:1305-6.

Manning AD, Fischer J, Lindenmayer DB. Scattered trees are keystone structures-implications for conservation. Biol Conserv. 2006;132:311-21.

Manning AD, Lindenmayer DB. Paddock trees, parrots and agricultural production: an urgent need for large-scale, long-term restoration in southeastern Australia. Ecol Manage Restor. 2009;10:126-35.

Martin K, Aitken KEH, Wiebe KL. Nest sites and nest webs for cavity-nesting communities in interior British Columbia, Canada: nest characteristics and niche partitioning. Condor. 2004;106:5-19.

Martin TE. Evolutionary determinants of clutch size in cavity-nesting birds: nest predation or limited breeding opportunities? Am Nat. 1993a;142:937-46. 
Martin TE. Nest predation and nest sites: new perspectives on old patterns. Bioscience. 1993b;43:523-32.

Masello JF, Quillfeldt P. Chick growth and breeding success of the Burrowing Parrot. Condor. 2002;104:574-86.

Moreno J, Carlson A. Clutch size and the costs of incubation in the Pied Flycatcher Ficedula hypoleuca. Orn Scand. 1989;20:123-8.

Myers N, Mittermeier RA, Mittermeier CG, da Fonseca GAB, Kent J. Biodiversity hotspots for conservation priorities. Nature. 2000;403:853-8.

Newton I. The role of nest sites in limiting the numbers of hole-nesting birds: a review. Biol Conserv. 1994;70:265-76.

Nilsson SV. The evolution of nest-site selection among hole-nesting birds: the importance of nest predation and competition. Orn Scand. 1984;15:167-75.

Olah G, Vigo G, Heinsohn R, Brightsmith DJ. Nest site selection and efficacy of artificial nests for breeding success of Scarlet Macaws Ara macao macao in lowland Peru. J Nat Conserv. 2014;22:176-85.

Ortiz-Catedral L, Brunton DH. Nesting sites and nesting success of reintroduced Red-crowned Parakeets (Cyanoramphus novaezelandiae) in Tiritiri Matangi Island, New Zealand. N Z J Zool. 2009;36:1-10.

Parra-Martínez SM, Renton K, Salinas-Melgoza A, Muñoz-Lacy LG. Tree-cavity availability and selection by a large-bodied secondary cavity-nester: the Military Macaw. J Ornithol. 2015;156:489-98.

Peña-Foxon M, Ippi S, Díaz IA. First nesting records of the endemic Slenderbilled Parakeet (Enicognathus leptorhynchus) in southern Chile. Ornitol Neotrop. 2011;22:103-10

Perry DR. A method of access into the crowns of emergent and canopy trees. Biotropica. 1978;10:155-7.

Pinho JB, Nogueira FMB. Hyacinth Macaw (Anodorhynchus hyacinthus) reproduction in the northern Pantanal, Mato Grosso, Brazil. Ornitol Neotrop. 2003;14:29-38.

Pitts TD. Effects of nest box size on Eastern Bluebird nests. J Field Ornithol. 1988;59:309-444.

Purcell KL, Verner J, Oring LW. A comparison of the breeding ecology of birds nesting in boxes and tree cavities. Auk. 1997;114:646-56.

Reid JM, Managhan P, Ruxton GD. The consequences of clutch size for incubation conditions and hatching success in Starlings. Funct Ecol. 2000;14:560-5.

Rendell WB, Robertson RJ. Nest site characteristics, reproductive success and cavity availability for Tree Swallows breeding in natural cavities. Condor. 1989;91:875-85.

Renton K, Salinas-Melgoza A, De Labra-Hernández M, de la Parra-Martínez SM. Resource requirements of parrots: nest site selectivity and dietary plasticity of Psittaformes. J Ornithol. 2015. doi:10.1007/s10336-015-1255-9.

Renton K, Salinas-Melgoza A. Climatic variability, nest predation, and reproductive output of Lilac-crowned Parrots (Amazona finschi) in tropical dry forest of western Mexico. Auk. 2004;121:1214-25.

Renton K. Agonistic interactions of nesting and nonbreeding macaws. Condor. 2004;106:354-62.

Ridgely RS, Allnutt TF, Brooks T, McNicol DK, MehIman DW, Young BE, Zook JR. Digital distribution maps of the birds of the western hemisphere, version 2.1. Arlington: NatureServe; 2005.

Rinke D. The reproductive biology of the Red Shining Parrot Prosopeia tabuensis on the island of'Eua, Kingdom of Tonga. Ibis. 1989;131:238-49.

Rivera L, Politi N, Bucher EH. Nesting habitat of the Tucuman Parrot Amazona tucumana in an old-growth cloud-forest of Argentina. Bird Conserv Int. 2011;22:398-410.

Salas C, García O. Modeling height development of mature Lophozonia obliqua. For Ecol Manage. 2006;229:1-6.

Salas C, LeMay V, Núñez P, Pacheco P, Espinosa A. Spatial patterns in an oldgrowth Lophozonia obliqua forest in south-central Chile. For Ecol Manage. 2006;231:38-46.

Sanz V. Análisis multiscalar y multivariado para evaluar la susceptibilidad de los nidos de psitácidos a la depredación: un ejemplo con la cotorra cabeciamarilla (Amazona barbadensis). Ornitol Neotrop. 2008;19(Suppl.):123-34.

Saunders DA, Mawson PR, Dawson R. Use of tree hollows by Carnaby's Cockatoo and the fate of large hollow-bearing trees at Coomallo Creek, Western Australia, 1969-2013. Biol Conserv. 2014;177:185-93.

Saunders DA, Smith GT, Rowley I. The availability and dimensions of tree hollows that provide nest sites for Cockatoos (Psittaciformes) in Western Australia. Aust Wildl Res. 1982;9:541-56.

Servicio Agricola y Ganadero (SAG). La Ley de Caza y su Reglamento. Santiago: Servicio Agricola y Ganadero; 2008.

Shoji A, Elliot KH, Aris-Brosou S, Wilson RP, Gaston AJ. Predictors of incubation costs in seabirds: an evolutionary perspective. Ibis. 2015;157:44-53.

Smith CC, Fretwell SD. The optimal balance between size and number of offspring. Am Nat. 1974;108:499-506.

Snyder NFR, Wiley JW, Kepler CB. The parrots of Luquillo: natural history and conservation of the Puerto Rican Parrot. Los Angeles: Western Foundation of Vertebrate Zoology; 1987.

Sockman KW, Schwabl H. Hypothermic tolerance in an embryonic American Kestrel (Falco sparverius). Can J Zool. 1998;76:1399-402.

Sokal RR, Rohlf FJ. Biometry. New York: W.H. Freeman; 1981.

Tews J, Brose U, Grimm V, Tielborger K, Wichmann MC, Schwager M, Jeltsch F. Animal species diversity driven by habitat heterogeneity/diversity: the importance of keystone structures. J Biogeogr. 2004;31:79-92.

Van Balen JH. The relationship between nest-box size, occupation and breeding parameters of the Great Tit Parus major and some other hole-nesting species. Ardea. 1984;70:1-24.

Veblen TT, Ashton DH, Schlegel FM. Tree regeneration strategies in a lowland Nothofagus-dominated forest in south-central Chile. J Biogeogr. 1979:6:329-40.

Veblen TT, Schlegel FM, Escobar B. Structure and dynamics of old-growth Nothofagus forests in the Valdivian Andes, Chile. J Ecol. 1980;68:1-31.

Webb DR. Thermal tolerance of avian embryos: a review. Condor. 1987:89:874-98.

Wesołowski T. Lessons from long-term hole-nester studies in a primeval temperate forest. J Ornithol. 2007;148(Suppl.):S395-405.

Whitacre DF. Additional techniques and safety hints for climbing tall trees, and some equipment and information sources. Biotropica. 1981;13:286-91.

White TH Jr, Abreu-González W, Toledo-González M, Torres-Báez P. Artificial nest cavities for Amazona parrots. Wildl Soc Bull. 2005;33:760-5.

White TH Jr, Brown GG, Collazo JA. Artificial cavities and nest site selection by Puerto Rican Parrots: a multiscale assessment. Avian Conserv Ecol. 2006;1:5. http://www.ace-eco.org/vol1/iss3/art5/.

White TH Jr, Collazo JA, Dinsmore SJ, Llerandi-Román I. Niche restriction and conservatism in a Neotropical psittacine: the case of the Puerto Rican Parrot. In: Devore B, editor. Habitat loss: causes, effects on biodiversity and reduction strategies. New York: Nova Science; 2014. p. 1-83.

Wiebe KL. Microclimate of tree cavity nests: is it important for reproductive success in Northern Flickers? Auk. 2001;118:412-21.

Williams JB, Ricklefs RE. Egg temperature and embryo metabolism in some high-latitude Procellariiform birds. Physiol Zool. 1984;57:118-27. 